\title{
Analyses of process parameters influence on the drilling process by using carbide drills for steel St52-3
}

\author{
Ioan Alexandru Popan ${ }^{1, *}$, Alina Ioana Popan ${ }^{1}$, Sorin Cosmin Cosma ${ }^{1}$, and Alexandru \\ Carean $^{1}$ \\ ${ }^{1}$ Technical University of Cluj-Napoca, B-dul. Muncii, No. 103-105, Cluj-Napoca, Romania
}

\begin{abstract}
The influence of cutting parameters on the hole quality made using a new type of carbide drill, RT100 U, has been analysed experimentally and analytically. The drilling process is a common application in industrial environments and it has to be established at high accuracy and short time. The influence of process parameters (cutting speed and feed rate) on dimensional accuracy and surface roughness is analysed. The experiment was made by using external cooling and canned cycles (G81). On this experimental study was analysed the effect of feed rate onto the chip shape.
\end{abstract}

\section{Introduction}

In this paper a new type of carbide drill, made by Guhring Company is analysed. The RT100 U drill has 2 flutes and a FIREX coated. It has a special designed to obtain a high penetration rate, a high holes accuracy and good surface quality.

In drilling process a significant amount of heat is generated because of the friction between tool and workpiece. For increasing the productivity, intensification of cutting parameters, techniques for cooling the process is needed [1].

Flood machining is a common technique in which a large quantity of cutting fluid is applied to the cutting tool and workpiece. Dry machining, cryogenic machining and Minimum Quantity Lubrication (MQL) are some alternative methods, more environments friendly [2 - 4].

On this paper the flood machining is chose, because is one of the most often cooling method used on industry. This type of cooling comes with improving of surface quality and can increase the tool life $[4,5]$. Also the manufacturer recommends flood machining for this type of drill.

A large number of drilling cycles are used on CNC drilling to improve the process. The most often met canned cycles are: (G81) used for simple drilling/spot drilling operations, (G83) peck drilling, this technique makes deep-hole drilling easy and economical and a chip-breaking canned cycle (G73). The canned cycles (G81) is used for many drilling operation because is the most efficient [6-8].

${ }^{*}$ Corresponding author: ioan.popan@.tcm.utcluj.ro 
The RT100 U drill is for general use and the manufacturer recommends some general process parameters. The manufacturer catalogues recommend using for drilling of a carbon steel St52-3 a cutting speed of 70-110 m/min and a feed rate of 0.05-0.4 mm/rev [1].

During cutting process, when the process parameters are wrong selected can appear chip control problems, low surface quality and low accuracy. By using a high cutting speed and a low feed rate can determine a bad chip evacuation and a tool broken $[2,6,9,10]$.

This paper presents the effects of process parameters (cutting speed and feed rate) on quality characteristics of holes made using this drill.

\section{Cutting tool and workpiece material}

A carbide drill RT100U/DIN653 (presented in fig. 1) made by Guhring Company was chosen for experimental research. The RT100 U style drill has 2 flute and FIREX coated. It is designed for high penetration rate to increase the productivity and increase the holes quality. The drill has a self-cantering $140^{\circ} \mathrm{SU}$ point, which eliminates the need for preliminary spot drill operations [1]. A new drill shape, RH Helix was developed to create short chips and a good chips evacuation. The wide-open flute was design in order to have short chip formation ant to eliminate the peck drilling cycle [1].

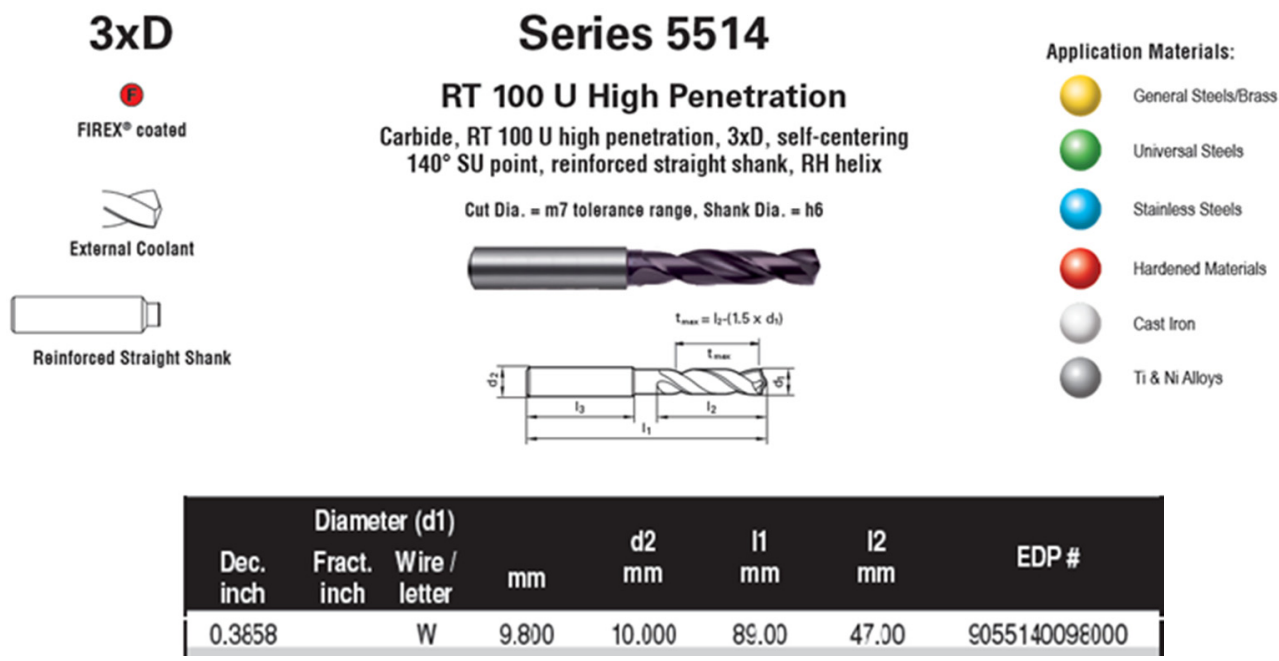

Fig. 1. The carbide drill RT100U.

The structural steel DIN ST52-3 (W.Nr 1.0580) was selected for this experiment. The chemical composition (reference value \%) are: C: $0-0.22$; $\mathrm{Si}: 0-0.55 \mathrm{Mn}: 0-1.6 \mathrm{P}: 0-$ 0.035 ; and S: $0-0.035$. This type of steel is often used for common applications and structural assemblies.

\section{Experimental procedures}

The Design of Experiment (DOE) methodology was used for the experiments. In this analyse a Central Composite Design (CCD) with two factors was chosen. The variation range of the input parameters is: cutting speed $=70-110 \quad[\mathrm{~m} / \mathrm{min}] ;$ feed rate $=0.05-0.4$ $[\mathrm{mm} / \mathrm{rev}]$. The values of input parameters (cutting speed and feed rate) are presented in Table 1. 
Table 1. The combination of the process parameters.

\begin{tabular}{|c|c|c|}
\hline No. & $\begin{array}{c}\text { Cutting speed } \\
{[\mathbf{m} / \mathbf{m i n}]}\end{array}$ & $\begin{array}{c}\text { Feed rate } \\
{[\mathbf{m m} / \mathbf{r e v}]}\end{array}$ \\
\hline 1. & 90 & 0.05 \\
\hline 2. & 90 & 0.23 \\
\hline 3. & 70 & 0.23 \\
\hline 4. & 90 & 0.23 \\
\hline 5. & 75.86 & 0.35 \\
\hline 6. & 90 & 0.4 \\
\hline 7. & 90 & 0.23 \\
\hline 8. & 90 & 0.23 \\
\hline 9. & 104.14 & 0.1 \\
\hline 10. & 90 & 0.23 \\
\hline 11. & 104.14 & 0.35 \\
\hline 12. & 75.86 & 0.1 \\
\hline 13. & 110 & 0.23 \\
\hline
\end{tabular}

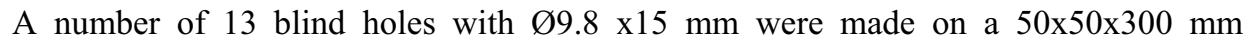
material. The experimental tests were made using a CNC vertical processing machine HAAS, with a motor power of $24 \mathrm{~kW}$, operating at max. 21,000 rev/min. For the tests an external cooling system was used. The type of cutting fluid is CASTROL SYNTILO 9954.

A mechanical vise (fig. 2) was used for clamping the workpiece and a Weldon clamping device with a high rigidity, (fig. 3) to clamp the drill. The experimental stand is presented in figure 4.

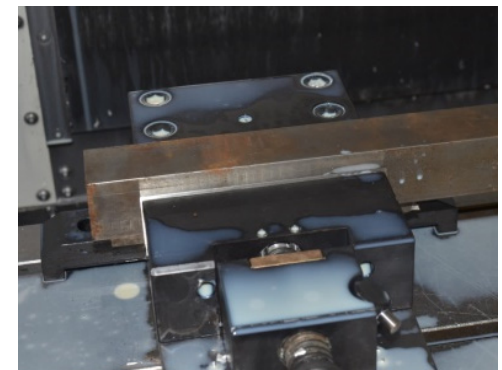

Fig. 2. The clamping system used for material fixing.

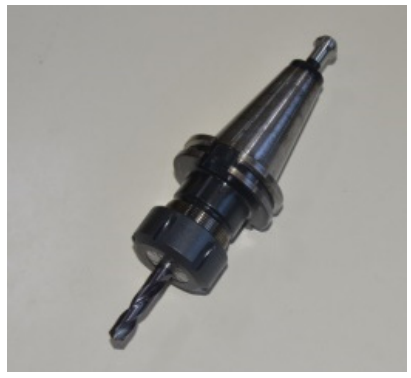

Fig. 3. The Weldon clamping system used for fixing the drill. 


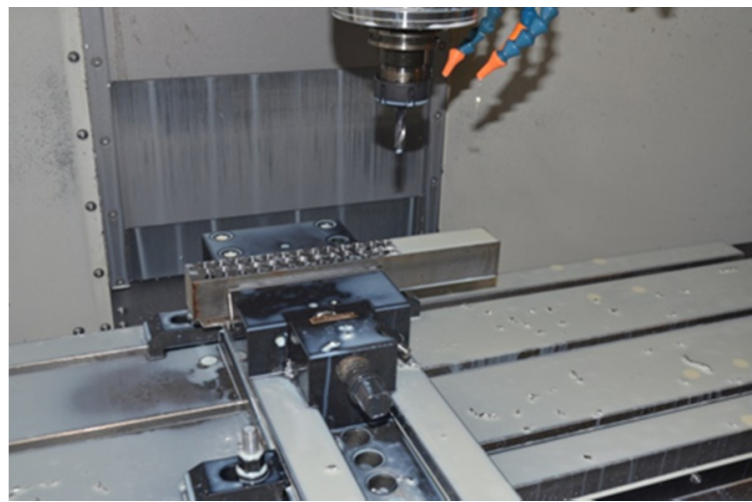

Fig. 4. Experimental stand (vise, drill, work piece and milling machine).

Using 3D measurement equipment, type 3D Aberlink (fig. 5), the dimensional deviation and cylindricity deviation were measured. A Mitutoyo Surftest SJ-210 was used for measuring the surface roughness (Ra), (fig. 6). The surface roughness measurements were repeated for three times for each hole. The measurements were made in axial direction for a length of $5 \mathrm{~mm}$ in the middle of the hole.

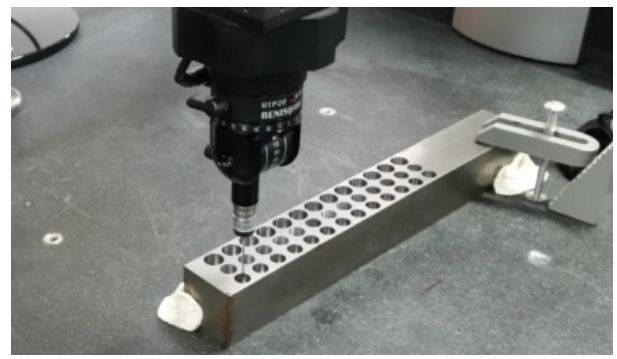

Fig. 5. Dimensional measurements.

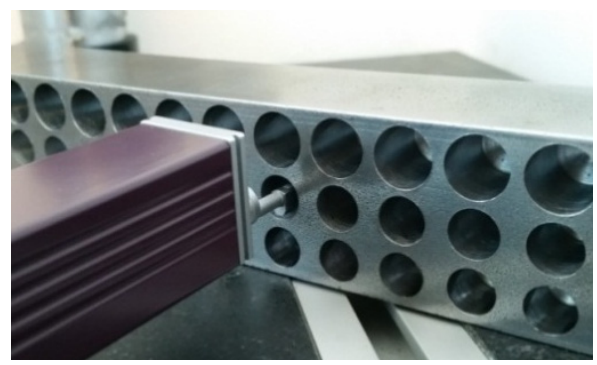

Fig. 6. Surface roughness measurements.

The experimental results obtained in different test conditions are presented in table 2 . Using Design Expert software the analysis of the experimental values and calculation of its coefficients, were made.

Table 2. Experimental results at different test conditions.

\begin{tabular}{|c|c|c|c|c|c|}
\hline No. & $\begin{array}{c}\text { Cutting speed } \\
{[\mathbf{m} / \mathbf{m i n}]}\end{array}$ & $\begin{array}{c}\text { Feed rate } \\
{[\mathbf{m m} / \mathbf{r e v}]:}\end{array}$ & $\begin{array}{c}\text { Roughness } \\
\text { Ra }[\boldsymbol{\mu m}]:\end{array}$ & $\begin{array}{c}\text { Dimensional } \\
\text { deviation }[\mathbf{m m}]:\end{array}$ & $\begin{array}{c}\text { Cylindricity } \\
\text { deviation }[\mathbf{m m}]:\end{array}$ \\
\hline 1 & 90 & 0.05 & 0.49 & 0.008 & 0.022 \\
\hline 2 & 90 & 0.23 & 1.1 & 0.025 & 0.009 \\
\hline 3 & 70 & 0.23 & 1.17 & 0.03 & 0.01 \\
\hline 4 & 90 & 0.23 & 1.18 & 0.026 & 0.013 \\
\hline 5 & 75.86 & 0.35 & 0.26 & 0.054 & 0.032 \\
\hline 6 & 90 & 0.4 & 1.17 & 0.04 & 0.006 \\
\hline 7 & 90 & 0.23 & 1.08 & 0.022 & 0.009 \\
\hline 8 & 90 & 0.23 & 1.09 & 0.023 & 0.01 \\
\hline 9 & 104.14 & 0.1 & 0.53 & 0.022 & 0.009 \\
\hline 10 & 90 & 0.23 & 1.15 & 0.025 & 0.01 \\
\hline 11 & 104.14 & 0.35 & 0.31 & 0.083 & 0.05 \\
\hline 12 & 75.86 & 0.1 & 0.297 & 0.024 & 0.041 \\
\hline 13 & 110 & 0.23 & 0.45 & 0.028 & 0.014 \\
\hline
\end{tabular}




\section{Results and discussions}

Studying the influence of process parameters on the quality characteristics of the holes was based on mathematical models developed using RSM (Response Surface Methodology).

\subsection{Effect of machining parameters on surface roughness}

Starting from Pareto ANOVA table was obtained for surface roughness modulation a Quadratic Model is significant. Based on this empirical mathematical model the variation curves of surface roughness according to process parameters were outlined.

In figure 7 is presented the dependence of the cutting speed and surface roughness. It is noted that increasing the cutting speed from 75 to $104 \mathrm{~m} / \mathrm{min}$, the surface roughness increases from 0.9 to $1.1 \mu \mathrm{m}(90 \mathrm{~m} / \mathrm{min})$ and decreases to $0.7 \mu \mathrm{m}$. The analyses were made using a $0.23 \mathrm{~mm} / \mathrm{rev}$ feed rate.

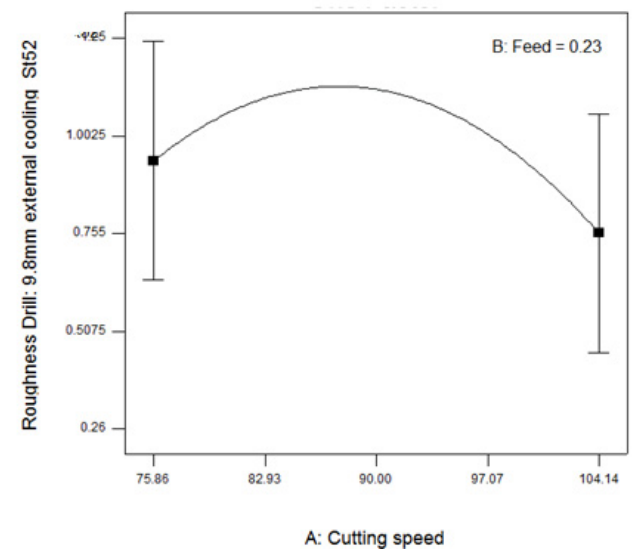

Fig.7. Effect of cutting speed $(\mathrm{m} / \mathrm{min})$ on surface roughness $(\mathrm{Ra} / \mu \mathrm{m})$.

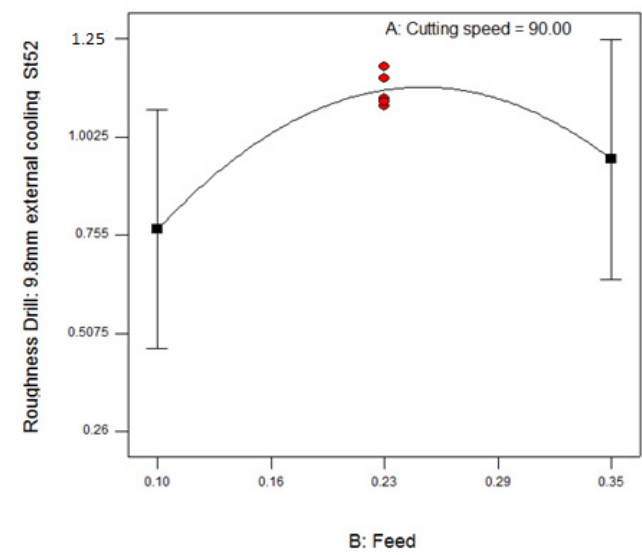

Fig.8. Effect of feed rate $(\mathrm{mm} / \mathrm{rev})$ on surface roughness $(\mathrm{Ra} / \mu \mathrm{m})$.

In figure 8 the effect of feed rate on surface roughness is presented for a constant cutting speed $90 \mathrm{~m} / \mathrm{min}$. Increasing the feed rate from 0.1 to $0.35 \mathrm{~mm} / \mathrm{rev}$, the surface roughness increases from 0.7 to $1.2 \mu \mathrm{m}$ and decreases up to $0.8 \mu \mathrm{m}$.

\subsection{Effect of machining parameters on the hole dimensional deviation}

For dimensional and cylindricity deviations a linear model form ANOVA analysis was obtained. Based on this linear mathematical model the variation curves of dimensional deviation according to process parameters were drawn.

In figure 9 is presented the effect of cutting speed onto the hole dimensional deviation, the feed rate is $0.23 \mathrm{~mm} /$ rot. Increasing the cutting speed from 75 to $104 \mathrm{~mm} / \mathrm{min}$ can be observed that dimensional deviation increases from 0.028 to $0.035 \mathrm{~mm}$. In conclusion, the cutting speed does not have a strong effect on dimensional deviation. 


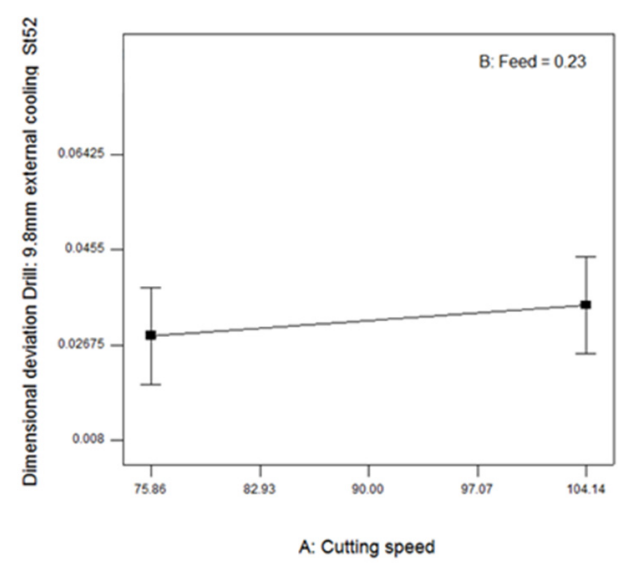

Fig.9. Effect of cutting speed $(\mathrm{m} / \mathrm{min})$ on dimensional deviation ( $\mathrm{mm})$.

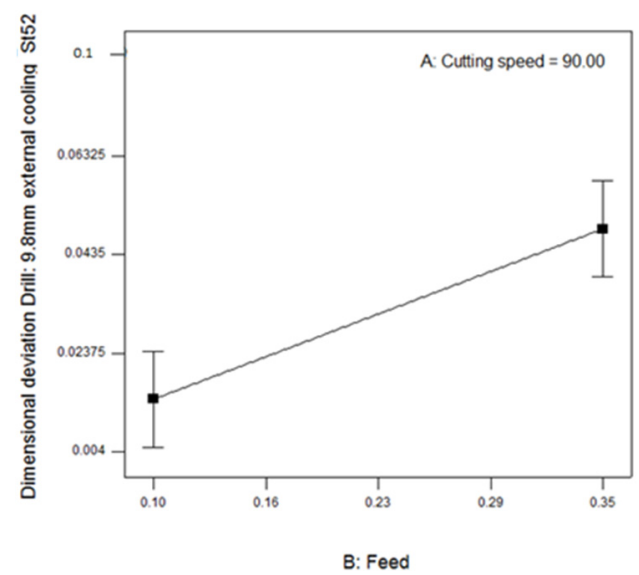

Fig.10. Effect of feed rate $(\mathrm{mm} / \mathrm{rev})$ on dimensional deviation $(\mathrm{mm})$.

The effect of feed rate on dimensional deviation for a $90 \mathrm{~m} / \mathrm{min}$ constant cutting speed is shown in figure 10 . Increasing the feed rate from 0.1 to $0.35 \mathrm{~mm} / \mathrm{rev}$ the dimensional deviation increases from 0.004 to $0.04 \mathrm{~mm}$.

\subsection{Effect of machining parameters on the hole cylindricity deviation}

Based on a linear mathematical model the variation curves of cylindricity deviation according to process parameters were outlined.

In figure 11 is presented the effect of cutting speed on the hole cylindricity deviation, the feed rare is $0.23 \mathrm{~mm} /$ rot. By increasing the cutting speed from 75 to $104 \mathrm{~mm} / \mathrm{min}$ can be observed the cylindricity deviation decreases from 0.02 to $0.017 \mathrm{~mm}$.

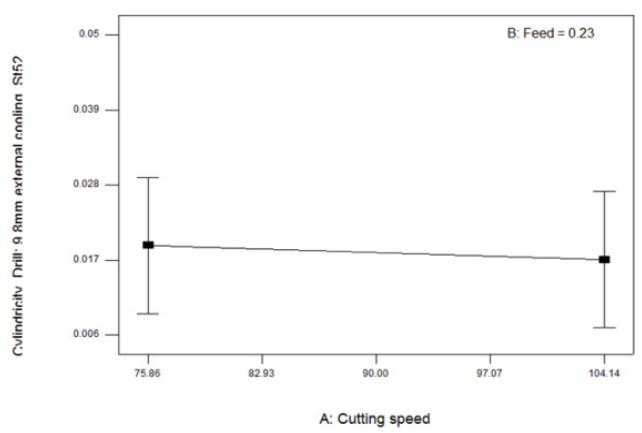

Fig.11. Effect of cutting speed $(\mathrm{m} / \mathrm{min})$ on cylindricity deviation ( $\mathrm{mm})$.

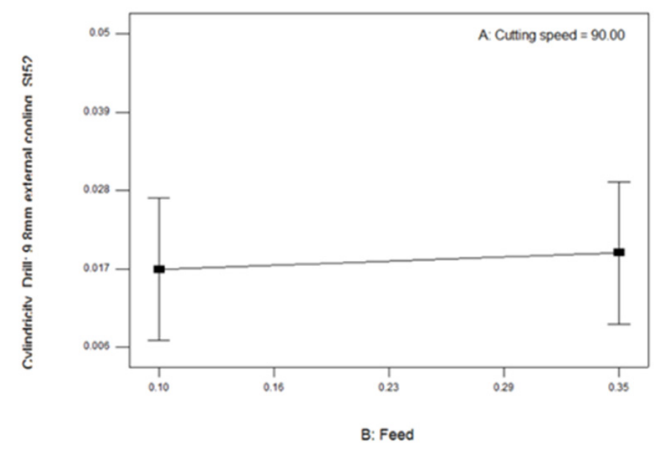

Fig.12. Effect of feed rate $(\mathrm{mm} / \mathrm{rev})$ on cylindricity deviation $(\mathrm{mm})$.

In figure 12 is presented the effect of feed rate onto the hole cylindricity deviation, for $90 \mathrm{~m} / \mathrm{min}$ constant cutting speed. Increasing the feed rate from 0.1 to $0.35 \mathrm{~mm} / \mathrm{rev}$ can be observed the cylindricity deviation increases from 0.017 to $0.019 \mathrm{~mm}$.

\section{Chip shape analysis}

In drilling process the chip control is important, because a wrong chip evacuation can generate a low surface quality, low dimensional accuracy or even tool brake [13]. 
On this experimental study was analysed the effect of feed rate onto the chip shape. The chip shape was analysed for three values of feed rate: $0.05 ; 0.23$ and $0.4 \mathrm{~mm} / \mathrm{rev}$.

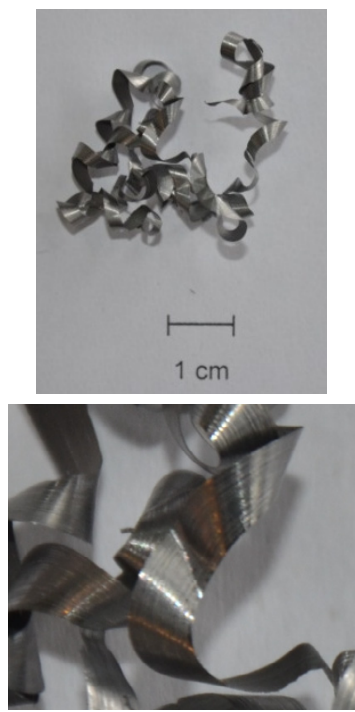

a. Feed rate: $0.05 \mathrm{~mm} / \mathrm{rev}$

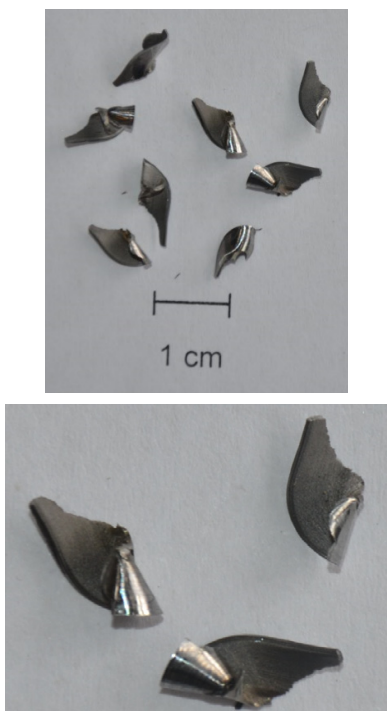

b. Feed rate: $0.23 \mathrm{~mm} / \mathrm{rev}$

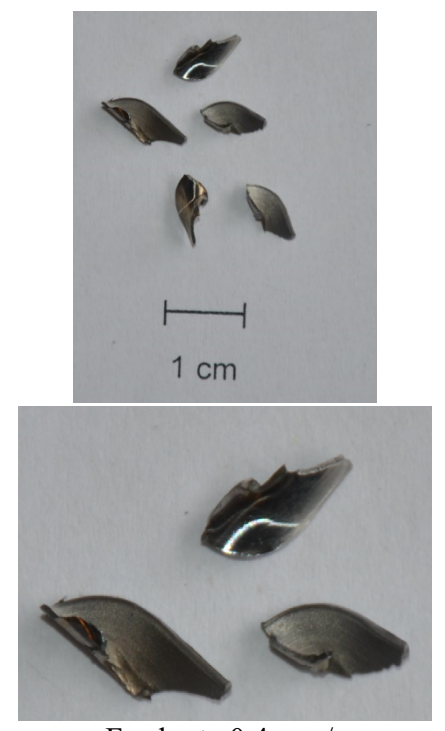

c. Feed rate: $0.4 \mathrm{~mm} / \mathrm{rev}$

Fig.13. The chip shape obtained for different values of the feed rate.

In the first case, using a feed rate of $0.05 \mathrm{~mm} / \mathrm{rev}$ and a cutting speed of $90 \mathrm{~m} / \mathrm{min}$, a spiral long chip (longer than $100 \mathrm{~mm}$ ), with about $0.1 \mathrm{~mm}$ thickness was obtained (fig. 13 . a). This chip shape is considered to be difficult for evacuation in drilling process. It can stick to drill (in clamping area), resulting a damaged workpiece surface.

In the second, using a feed rate of $0.23 \mathrm{~mm} / \mathrm{rev}$ and a cutting speed of $90 \mathrm{~m} / \mathrm{min}$, a short chip (about $10 \mathrm{~mm}$ ), with about $0.3 \mathrm{~mm}$ thickness was obtained (fig. 13.b). For a feed rate of $0.4 \mathrm{~mm} / \mathrm{rev}$ and a cutting speed of $90 \mathrm{~m} / \mathrm{min}$, a short chip (about10 $\mathrm{mm}$ ) with about 0.5 $\mathrm{mm}$ thickness was obtained (fig. 13.c). In this case the chip shape was the same with the one obtained using a $0.23 \mathrm{~mm} / \mathrm{rev}$ feed rate. This chip shape provides a very good chip evacuation in drilling. The result obtained from this experimental study it is concluded that to obtain a good chip evacuation it is necessary to use a feed rate over $0.2 \mathrm{~mm} / \mathrm{rev}$.

\section{Conclusions}

Based on the experimental results we can conclude the following:

- For improving the surface quality is recommended to increase the cutting speed and to decrease the feed rate. To obtain a surface quality around $0.8 \mu \mathrm{m}$ is recommended to use a cutting speed of $90 \mathrm{~mm} / \mathrm{min}$ and a feed rate $0.23 \mathrm{~mm} / \mathrm{rev}$;

- For decreasing the dimensional deviation is recommended to decrease the cutting speed and to decrease the feed rate. The dimensional deviation around $0.04 \mathrm{~mm}$ is resulted from the following parameters: cutting speed $75 \mathrm{~mm} / \mathrm{min}$ and feed rate $0.1 \mathrm{~mm} / \mathrm{rev}$;

- To decrease the cylindricity deviation is recommended to increase the cutting speed and decrease the feed rate. To obtain a cylindricity deviation around $0.017 \mathrm{~mm}$ is recommended cutting speed $104 \mathrm{~mm} / \mathrm{min}$ and feed rate $0.1 \mathrm{~mm} / \mathrm{rev}$.

Using the optimal process parameters, could be processed holes at a good surface quality (up to $\mathrm{Ra}=0.8 \mu \mathrm{m})$ and a high accuracy $(0.004 \mathrm{~mm}$ dimensional deviation and $0.01 \mathrm{~mm}$ cylindricity deviation). To obtain a good chip evacuation during the drilling process with this type of carbide drill, must be used a feed rate over $0.2 \mathrm{~mm} / \mathrm{rev}$. 
This research was funded by the HORIZON 2020 Project - AMaTUC, No.691787/01.01.2016

\section{References}

1. www.guhring.com

2. Y. Kaynak, H.E. Karaca, R.D. Noebe, I.S. Jawahir, Tool-wear analysis in cryogenic machining of NiTi shape memory alloys: a comparison of tool-wear performance with dry and MQL machining. Wear 306(1-2),51(2013)

3. S.Y. Hong, I. Markus, W.C. Jeong, New cooling approach and tool life improvement in cryogenic machining of titanium alloy Ti-6Al-4V. International Journal of Machine Tools \& Manufacture 41, 2245 (2001)

4. N.R. Dhar, S. Paul, A. B. Chattopadhyay, The influence of cryogenic cooling on tool wear, dimensional accuracy and surface finish in turning AISI 1040 and E4340C steels. Wear 249(10), 932(2001)

5. V. Krishnaraj, A. Prabukarthi, Optimization of machining parameter at high speed drilling of carbon fiber reinforced plastic (CFRP) laminates, Composites: Part B, 43: 1791(2012)

6. W.C. Chen, C.C. Tsao, Cutting performance of different coated twist drills. Journal of Materials Processing Technology, 88(1), 203(1999)

7. M.N. Islam, B. Boswell, Effects of canned cycles and cutting parameters on hole quality in cryogenic drilling of aluminium 6061-6T, International Journal of Chemical, Molecular, Nuclear, Materials and Metallurgical Engineering, 10(7), 857 (2016)

8. A. Prabukarthi, V. Krisharaj, Multi-objective optimization on drilling of titanium alloy (Ti6Al4V), Materials Science Forum, 763,29 (2013)

9. K.H. Park, A. Bealb, Tool wear in drilling of Composite/titanium stacks using carbide and polycrystalline diamond tools, Wear, 11-12, 2826(2011)

10. T. Xia, Y. Kaynak, C. Arvin, I.S. Jawahir, Cryogenic cooling-induced process performance and surface integrity in drilling CFRP composite material, The International Journal of Advanced Manufacturing Technology, 82 (1), 605,(2016).

11. L. Morovič, J. Milde, CAD model created from polygon mesh. In Applied Mechanics and Materials : Vol. $808=$ Modern Technologies in Manufacturing, Selected, Peer reviewed papers from the 12th International Conference on Modern Technologies in Manufacturing (MTeM),808, 233,(2015)

12. J. Peterka, L. Morovič, Optical 3D Scanning of Cutting Tools. In Applied Mechanics and Materials: 4th International Conference on Information Technology for Manufacturing Systems (ITMS), 663(2013)

13. L. Crişan, M. Pop Grigore, C. Neamţu, The influence of process temperature on geometrical deviations at the drilling of carbon fiber reinforced composites. QualityAccess to Success, (2012)

14. A. Luca, N. Balc, A. Popan, V. Ceclan, N. Panc. Improving the quality of the parts made by rapid metal casting process. Academic Journal of Manufacturing Engineering, 12 (1), 82(2014) 